\title{
Colon Cancer Chemoprevention by Sage Tea Drinking: Decreased DNA Damage and Cell Proliferation
}

\author{
Dalila F. N. Pedro, ${ }^{1}$ Alice A. Ramos, ${ }^{1,2}$ Cristovao F. Lima, ${ }^{3}$ Fatima Baltazar ${ }^{4,5}$ \\ and Cristina Pereira-Wilson ${ }^{3 *}$ \\ ${ }^{1}$ Department of Biology, School of Sciences, University of Minho, 4710-057, Braga, Portugal \\ ${ }^{2}$ Laboratory of Cellular, Molecular and Analytical Studies, CIIMAR, University of Porto, 4050-123, Porto, Portugal (Present adress) \\ ${ }^{3}$ CITAB, Department of Biology, School of Sciences, University of Minho, 4710-057, Braga, Portugal \\ ${ }^{4}$ Life and Health Sciences Research Institute (ICVS), Health Sciences School, University of Minho, 4710-057, Braga, Portugal \\ ${ }^{5}$ ICVS/3B's - PT Government Associate Laboratory, Braga/Guimarães, Portugal
}

\begin{abstract}
Salvia officinalis and some of its isolated compounds have been found to be preventive of DNA damage and increased proliferation in vitro in colon cells. In the present study, we used the azoxymethane model to test effects of $S$. officinalis on colon cancer prevention in vivo. The results showed that sage treatment reduced the number of ACF formed only if administered before azoxymethane injection, demonstrating that sage tea drinking has a chemopreventive effect on colorectal cancer. A decrease in the proliferation marker Ki67 and in $\mathrm{H}_{2} \mathrm{O}_{2}$-induced and azoxymethane-induced DNA damage to colonocytes and lymphocytes were found with sage treatment. This confirms in vivo the chemopreventive effects of $S$. officinalis. Taken together, our results show that sage treatment prevented initiation phases of colon carcinogenesis, an effect due, at least in part, to DNA protection, and reduced proliferation rates of colon epithelial cell that prevent mutations and their fixation through cell replication. These chemopreventive effects of $S$. officinalis on colon cancer add to the many health benefits attributed to sage and encourage its consumption. Copyright @ 2015 John Wiley \& Sons, Ltd.
\end{abstract}

Keywords: Salvia officinalis tea; colon cancer; DNA damage; comet assay.

Abbreviations used: ACF, aberrant crypt foci; APC, adenomatous polyposis coli; AOM, azoxymethane; CDNB, 1-chloro-2,4-dinitrobenzene; CRC, colorectal cancer; CYP2E1, cytochrome P450 2E1; GSH, glutathione; GST, glutathione-S-transferase; MAM, methylazoxymethanol; PNP, $p$-nitrophenol; SO, Salvia officinalis.

\section{INTRODUCTION}

Colorectal cancer (CRC) is one of the most common cancers worldwide and one of the leading causes of death by cancer in developed countries. Diet, particularly if rich in saturated fat, has been found to be an important risk factor in the development of this malignancy (Padidar et al., 2012; Tang et al., 2012). A diet rich in fruits and vegetables has been shown, on the other hand, to have preventive effects on colon cancer (Pan et al., 2011). In agreement with this, a variety of naturally occurring plant compounds, such as phenolic acids, flavonoids, and carotenoids, have been found to prevent aberrant crypt foci (ACF) formation, the precursor lesions of colon cancer (Mori et al., 2004; Pan et al., 2011). Salvia officinalis (SO; sage) is a common plant in southern Europe, traditionally used to prepare herbal tea or as a condiment in Mediterranean countries. It has also been attributed medicinal properties such as, antiseptic, antiinflammatory and antihyperglycemic activities, and has a high content of biologically active compounds (Miura et al., 2002;

\footnotetext{
* Correspondence to: Cristina Pereira-Wilson, CITAB, Department of Biology, School of Sciences, University of Minho, 4710-057 Braga, Portugal.

E-mail: cpereira@bio.uminho.pt
}

Topcu, 2006). The water extract of SO used in the present study contains rosmarinic acid and luteolin7-glucoside which are the major phenolic compounds of the species, while 1,8-cineole, cis-thujone, trans-thujone, camphor and borneol are the major volatile compounds present (Lima et al., 2005). Previous studies from our lab have shown chemopreventive effects of SO extract in vitro by protection against oxidative DNA damage and stimulation of DNA repair (Ramos et al., 2010a), and also that SO inhibited cell proliferation in HCT15, a colon cancer-derived cell line (Xavier et al., 2009). SO extract shows promising in vitro anticancer effects. However it is known that the in vitro effects are not always seen in vivo. Some in vivo studies have shown antioxidant properties of this extract not only in animals (Lima et al., 2005) but also in humans (Sa et al., 2009). Nevertheless, to our knowledge, no studies have shown the chemopreventive effect of SO on colon cancer, and to endorse the consumption of SO tea as beneficial to the public health as chemopreventive in vivo studies are needed.

A combination of induction of DNA damage, defective DNA repair systems, and failure to stop the cell cycle to correct DNA before it is passed on to the next generation of cells are contributing factors to carcinogenesis (Lord and Ashworth, 2012). DNA damage is constantly being inflicted to cells and, when the repair capacity is overwhelmed, it becomes the underlying 
cause of mutations. Critically, mutations may occur in key genes that control apoptosis and cell proliferation, giving these cells growth advantage, eventually leading to cancer (Peltomaki, 2001). The formation of ACF is the reflex of increased cell proliferation, which may result from DNA damage and occurrence of mutations in the colon mucosa. Many studies use chemical induction of ACF in rodents as a model of sporadic CRC to study the chemopreventive or carcinogenic potential of natural or synthetic compounds. The DMH/azoxymethane (AOM) model shares many similarities to human sporadic colon cancer and provides a good experimental model to study chemopreventive effects, including those produced by dietary agents. Other animal exist that mimic hereditary CRC, such as the transgenic adenomatous polyposis coli (APC) $\mathrm{min} /+$ mice model and Pirc (polyposis in the rat colon) rat model for familial adenomatous polyposis coli syndrome, and heterozygous or homozygous mice for DNA mismatch repair genes as a Lynch syndrome model (Johnson and Fleet, 2013).

In the present study, we evaluated the potential effect of SO water extract (sage tea) as a chemopreventive agent against the initiation and/or promotion of AOMinduced colon cancer in vivo. The preventive mechanisms were further characterized at the level of drug metabolism, proliferative markers, as well as at the level of colonocyte and lymphocyte DNA protection. The results confirmed the already observed in vitro anti CRC effect in an in vivo model.

\section{MATERIAL AND METHODS}

Animals. Female Fischer 344 rats, 3-weeks-old, were obtained from Charles River Laboratories and kept in quarantine during 1 week. Throughout the whole experiment, the animals had free access to food, an AIN76-based rat chow. Animals were weighed once a week during the whole experiment, and food and water/sage tea consumption was registered three times a week. The experiments were carried out according to the regulations of national authorities for handling laboratory animals (Veterinary General Directive Board, Ministry of Agriculture, Rural Development and Fishing) and European Community Council Directive 86/609/EEC.

Salvia officinalis water extract preparation. Salvia officinalis water extract $(13.3 \mathrm{~g} / \mathrm{L})$ was routinely prepared as an infusion by pouring $450 \mathrm{~mL}$ of boiling water onto $6 \mathrm{~g}$ of the freeze dried plant material and allowing to steep for $5 \mathrm{~min}$ (Lima et al., 2005). The sage water extract was prepared fresh daily in order to avoid oxidation or other type of compound degradation, using plant material always from the same batch. The composition of the extract has been published elsewhere (Lima et al., 2005), and the major phenolic compounds are rosmarinic acid and luteolin-7-glucoside (Table 1).

Experimental design. Rats were divided into six groups (Fig. 1A). Groups 2 [Sage (pre)] and 4 (Sage + AOM) had access to SO water extract instead of water (Groups 1 and 3 ) during the first 2 weeks. These two groups were used to evaluate the effects of sage water extract on initiating steps of the carcinogenic process. Groups 5 [Sage (post)] and 6 (AOM + Sage) had access to sage water extract during the last 4 weeks of the experiment. These two groups were used to investigate the potential of this extract to affect post-initiating steps of CRC progression. At the second and third week, Groups 3 (Water $+\mathrm{AOM}), 4$ and 6 received a subcutaneous injection of AOM $(15 \mathrm{mg} / \mathrm{kg})$ in saline $(0.9 \%)$. The other three groups received an injection of the vehicle. Seven weeks later, the animals were sacrificed, and the colons removed for ACF and immunohistochemistry.

For colonocyte and lymphocyte isolation, as well as for assessment of liver parameters, four additional groups of rats (Fig. 1B) were sacrificed a day after AOM injection. For lymphocyte isolation, blood from all animals was collected in 5\% EDTA and followed to the isolation protocol. The colon was also removed and washed in HBSS buffer $(\mathrm{NaCl}, 8.0 \mathrm{~g} / \mathrm{L} ; \mathrm{KCl}$, $0.4 \mathrm{~g} / \mathrm{L} ; \quad \mathrm{Na}_{2} \mathrm{HPO}_{4} .12 \mathrm{H}_{2} \mathrm{O}, \quad 0.12 \mathrm{~g} / \mathrm{L} ; \mathrm{KH}_{2} \mathrm{PO}_{4} .3 \mathrm{H}_{2} \mathrm{O}$,

Table 1. Main compounds found in SO water extract (Lima et al., 2005)

\begin{tabular}{|c|c|c|c|c|c|c|c|}
\hline \multirow[b]{2}{*}{ Compound } & \multirow{2}{*}{$\frac{\text { Phenolic acids }}{\text { Rosmarinic acid }}$} & \multirow{2}{*}{$\frac{\text { Flavonoids }}{\text { Luteolin-7-glucoside }}$} & \multicolumn{5}{|c|}{ Volatile compounds } \\
\hline & & & Cis-thujone & 1,8-cineole & Borneol & Camphor & Trans-thujone \\
\hline $\mathrm{mg} / \mathrm{mL}$ & 362.0 & 115.3 & 1.7 & 0.9 & 0.7 & 0.5 & 0.3 \\
\hline
\end{tabular}
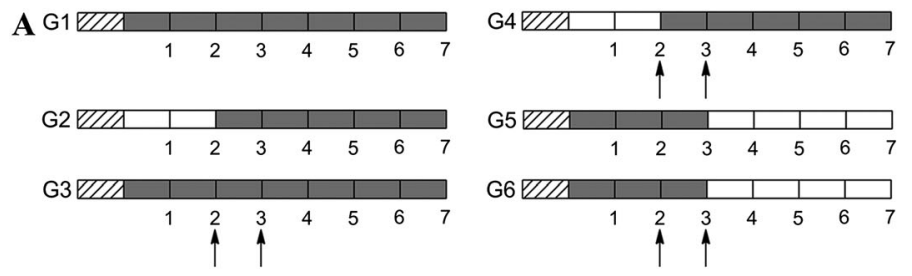

B
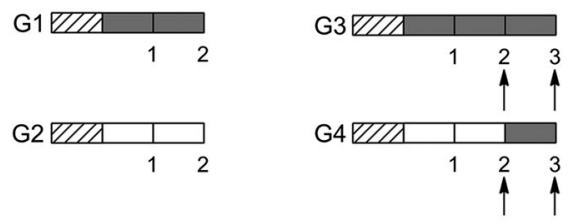

एU] Quarantine $\square$ Water $\square$ Sage water extract $\uparrow$ AOM injection

Figure 1. Experimental plan 1 (A). G1 - water, G2 - sage (pre), G3 - water + AOM, G4-sage + AOM, G5 - sage (post), G6 - AOM + sage. experimental plan 2 (B). G1 - water, G2 - sage, G3 - water + AOM, G4 - sage + AOM. All rats were kept in quarantine for 1 week. AOM injections were given to Groups 3,4 and 6 at weeks 2 and 3. Saline injections were given to the other three groups. At the end of the seventh week all animals were sacrificed by decapitation. 
$0.078 \mathrm{~g} / \mathrm{L} ; \quad \mathrm{NaHCO}_{3}, \quad 0.35 \mathrm{~g} / \mathrm{L} ;$ HEPES, $\left.4.8 \mathrm{~g} / \mathrm{L}\right)$ for colonocyte isolation.

Identification and quantification of aberrant crypt foci. The colons were washed with ice cold phosphate buffered saline (PBS), cut open longitudinally, fixed in $3 \%(\mathrm{w} / \mathrm{v})$ paraformaldehyde for $24 \mathrm{~h}$ and then stored in ethanol.

For ACF identification and quantification, colons were stained with $0.05 \%(\mathrm{w} / \mathrm{v})$ methylene blue in PBS for $5 \mathrm{~min}$. ACF number and multiplicity (number of aberrant crypts in each ACF) were scored blindly using a light microscope.

Immunohistochemical analysis of aberrant crypt foci. Four $\mu \mathrm{m}$ sections were cut, deparaffinised and rehydrated. Antigen retrieval was performed using $10 \mathrm{mM}$ citrate buffer solution, $\mathrm{pH} 6.0$ at $98^{\circ} \mathrm{C}$ for $20 \mathrm{~min}$, and endogenous peroxidase inactivation was performed using $0.3 \%$ hydrogen peroxide for $10 \mathrm{~min}$. Sections were incubated with a protein blocking solution for $10 \mathrm{~min}$ and then incubated with primary antibody: Ki67 (1:100), Abcam, Cambridge, UK and APC (1:800) and $\beta$-catenin (1:100), Santa Cruz Biotechnology, Heidelberg, Germany. Next, the sections were incubated with Streptavidine Peroxidase for $10 \mathrm{~min}$ followed by development with 3,3'-diamino-benzidine (DAB + substrate System) during $10 \mathrm{~min}$. Immunohistochemistry was performed using the Streptavidin-biotin peroxidase complex system (UltraVision Large Volume Detection System Anti-Polyvalent, Horseradish Peroxidase, Lab Vision Corporation, Fremont, CA, USA). Counterstaining was performed with haematoxylin, and slides were permanently mounted. Ki67 positivestained cells were expressed as percentage of positive cells per total number of epithelial cells per crypt.

Microsomal fraction preparation for cytochrome P450 2E1 evaluation. To measure the activity and expression of cytochrome P450 2E1 (CYP2E1), liver microsomal fractions were isolated by differential centrifugation as previously described elsewhere (Barbier et al., 2000). Aliquots were frozen in liquid nitrogen and stored at $-80^{\circ} \mathrm{C}$ until further use.

Evaluation of cytochrome P450 2E1 activity. The activity of CYP2E1 can be measured spectrophotometrically by following, at $480 \mathrm{~nm}$, the conversion of $p$-nitrophenol to 4-nitrocatechol, as described by Allis and Robinson, 1994 (Allis and Robinson, 1994).

Cytochrome P450 2E1 protein expression. Protein concentration was quantified using with the Bradford Reagent purchased from Sigma using bovine serum albumin as a standard and $40 \mu \mathrm{g} / \mathrm{well}$ was separated by $12 \%$ SDS-PAGE and transferred to polyvinylidene difluoride membranes. A rabbit polyclonal antibody against CYP2E1 (StressGen, Ann Arbor, MI, USA) protein (1:5000) was used overnight at $4^{\circ} \mathrm{C}$, and secondary antibody incubation was performed with anti-rabbit antibody conjugated with IgG horseradish peroxidase. A chemiluminescence detection system (Chemi Doc XRS, Bio-Rad Laboratories, Inc, Hercules, CA, USA) and band area intensity was quantified using the Quantity One software (Bio-Rad).
Glutathione-S-transferase activity. Glutathione-S-transferase (GST) activity was measured in liver homogenates and was determined by following the formation of glutathione conjugate at $340 \mathrm{~nm}$ with 1-chloro-2,4dinitrobenzene as previously described by our group (Lima et al., 2005).

Colonocyte isolation. The colons were removed and washed with HBSS buffer and then with ice-cold incubation solution (glucose, $1 \mathrm{~g} / \mathrm{L}$; DTT, $1 \mathrm{mM}$; glutamic acid, $2.4 \mathrm{mM}$, dissolved in HBSS buffer). The colons were then cut open longitudinally and placed in $10 \mathrm{~mL}$ of incubation solution, with $2 \mathrm{mg}$ of proteinase $\mathrm{K}$ and $1.5 \mathrm{mg}$ of collagenase, for $10 \mathrm{~min}$ at $37^{\circ} \mathrm{C}$, stirring slightly and gassed with carbogen $\left(95 \% \mathrm{O}_{2}\right.$ and $\left.5 \% \mathrm{CO}_{2}\right)$. The obtained cell suspension was filtered with $70 \mu \mathrm{m}$ filters to separate the colonocytes. Next, $50 \mu \mathrm{L}$ of $5.88 \% \mathrm{CaCl}_{2}$ was added for each $5 \mathrm{~mL}$ of cell suspension, following a centrifugation at $200 \mathrm{~g}$ for $10 \mathrm{~min}$ at $4^{\circ} \mathrm{C}$. The pellet was resuspended in culture medium, and cells were counted and used to measure DNA damage by the comet assay.

Lymphocyte isolation. For lymphocyte isolation, the blood collected in EDTA solution was diluted in an equal volume of PBS buffer. This volume was added to a tube containing Ficoll, also in equal proportion, following a centrifugation at $1800 \mathrm{rpm}$ for $18 \mathrm{~min}, 18^{\circ} \mathrm{C}$. The lymphocyte layer was removed and transferred to another tube where PBS was added and another centrifugation was performed at $1800 \mathrm{rpm}$ for $10 \mathrm{~min}, 18^{\circ} \mathrm{C}$. The pellet was resuspended in medium, and cells were counted and used to measure DNA damage by the comet assay.

Evaluation of DNA damage by comet assay and in vitro oxidative damage induction. The alkaline version of the single cell gel electrophoresis (comet) assay was used to evaluate DNA damage (Collins, 2004). Briefly, 50000 cells were centrifuged for $1 \mathrm{~min}$ at $5000 \mathrm{rpm}$, resuspended in low-melting point agarose and spread onto agarose-coated slide using a cover slip. To study protection against AOM-induced DNA damage in colonocytes and lymphocytes, the standard comet assay was used. To study protection against in vitro $\mathrm{H}_{2} \mathrm{O}_{2}$-induced DNA damage, colonocytes from sage or water drinking animals were used. After spreading these colonocytes on the slides, the slides were placed in different concentrations of $\mathrm{H}_{2} \mathrm{O}_{2}$ solution $(25,50$ or $100 \mu \mathrm{M})$ or PBS (control), on ice for $5 \mathrm{~min}$. After $5 \mathrm{~min}$ at $4^{\circ} \mathrm{C}$, the cover slip was removed, and the slides were placed in lysis buffer $\left(\mathrm{NaCl}, 2.5 \mathrm{M} ; \mathrm{Na}_{2}\right.$ EDTA, $100 \mathrm{mM}$; Tris, $10 \mathrm{mM}$, $\mathrm{pH} 10)$ plus $1 \%$ Triton $\mathrm{X}-100$ for $1 \mathrm{~h}$ at $4^{\circ} \mathrm{C}$. Then, the slides were left in electrophoresis buffer $(\mathrm{NaOH}$, $300 \mathrm{mM} ; \mathrm{Na}_{2} \mathrm{EDTA}, 1 \mathrm{mM}, \mathrm{pH}>13$ ) for $40 \mathrm{~min}$ at $4^{\circ} \mathrm{C}$. The electrophoresis was run for $20 \mathrm{~min}$ at $4^{\circ} \mathrm{C}, 21 \mathrm{~V}$ $(0.8 \mathrm{~V} / \mathrm{cm})$ and $300 \mathrm{~mA}$. After the electrophoresis, the slides were placed in neutralization buffer (Tris Base, $0.4 \mathrm{M}, \mathrm{pH} 7.4$ ) for $15 \mathrm{~min}$, washed with water and dehydrated with ethanol. To each slide, $20 \mu \mathrm{L}$ of ethidium bromide was added, and 100 cells were counted under a fluorescent microscope and quantified by visual scoring and using Comet 4 image analysis system (Perceptive Instruments).

Statistical analysis. Statistical significances were determined using two-way analysis of variance, followed by 
Bonferroni post-test for the effects of sage tea on protection against oxidative DNA damage, and Student's $t$-test for all other data. Data were expressed as means \pm SEM. $P$ values $\leq 0.05$ were considered statistically significant.

\section{RESULTS AND DISCUSSION}

Diet is an important factor in colon carcinogenesis. It has been shown that fat and red meat can promote tumorigenesis. However, diet can also have a beneficial effect on colon cancer (Ramos et al., 2010b) and, in order to prevent this malignancy, dietary strategies that inhibit the formation or delay the progression of tumours are needed. In the present study, the chemopreventive potential of the water extract of sage, a plant with antioxidant properties (Lima et al., 2005; Lima et al., 2007b) that has been shown to have in vitro anticancer effects such as the ability to prevent DNA damage (Ramos et al., 2010a), was studied against $\mathrm{ACF}$ formation in the sporadic AOM-induced colon carcinogenesis model. As our group has various studies demonstrating the in vitro potential of this extract, the objective in this study was to test whether the in vitro effects are also present in vivo and correspond to a cancer preventive effect. We used the water extract and not an isolated compound of the extract to put emphasis on dietary strategies with whole compound mixtures and to study the food, in this case a tea, as a complex mixture. Treatment with sage tea before exposure to the carcinogen (AOM injection) significantly decreased the number of ACF formed, indicating a chemopreventive effect of this extract on the initiation phase of the carcinogenic process in the colon (Fig. 2A). The lack of effect of the extract when given after carcinogen injection (Fig. 2A) and on crypt multiplicity (average number of aberrant crypts in each focus) (Fig. 2B) indicates that after mutations set in, the herbal tea does not affect molecular mechanisms involved in promotional phases, at least not this early in the process. More prolonged studies with progression to fully developed tumours would be necessary to evaluate the potential of the herbal tea in advanced stages of carcinogenesis. Although genetic animal models are commonly used to obtain important information on familial colon carcinogenesis, the AOM-induced model is very useful in exploring the molecular mechanisms involved in sporadic CRC due to the similarities in the pathophysiology of the tumours with human colon tumours (Johnson and Fleet, 2013).

Beneficial effects of other plant foods have been found, for example, black tea and wine extracts, but not green tea have shown to protect against AOMinduced colon carcinogenesis in rats (Caderni et al., 2000) and theaflavin-2, a major compound found in black tea extract was shown to induce apoptosis in human colon cell lines (Gosslau et al., 2011). Butyrate may reduce the risk of CRC in a dose dependent manner by enhancing apoptosis for damaged cells without promoting the risk of tumorigenesis through increased cell proliferation (Toden et al., 2014). In a study by Andersson et al., 2008 (Andersson et al., 2008), ursolic acid, a pentacyclic triterpenoid also present in SO, was found to reduce the number of large ACF when given orally to rats during the initiation phase but not during the promotion/progression phase, results that are in agreement with our present study. Also, a study from our lab demonstrated that ursolic acid protects colon cells against DNA damage in vitro (Ramos et al., 2010b) as well as CRC progretion in vitro and in vivo.

Effects of our herbal tea on initiation may reflect decreased AOM toxicity due to (i) decreased bioactivation through CYP2E1, (ii) increased excretion through GST induction, (iii) DNA damage protection, and/or (iv) effects on cell proliferation (Xavier et al., 2013). CYP2E1 is involved in the in vivo activation of various carcinogens, including AOM, (Sohn et al., 2001), suggesting that agents that modify this enzyme's activity or expression levels may either promote or inhibit CRC through effects on formation of carcinogenic AOM derivatives. Based on this, effects of sage treatment on liver CYP2E1 activity and expression were evaluated, but none were found (Fig. 3). A decrease of CYP2E1 activity with AOM injection was found, but this decrease was only significant in the water drinking group (Fig. 3A). As demonstrated for other drugs, a decrease in CYP2E1 activity after a few hours (12-24h) of AOM administration may indicate increased AOM metabolism and CYP2E1 inactivation due to the high amount of free radicals produced (Lima et al., 2007a; Weber et al., 2003; Zhukov and Ingelman-Sundberg, 1999). Modulation of GST, a phase II enzyme, can increase carcinogen elimination before damage is carried out. In this study, and contrarily to what happened previously with mice (Lima et al., 2005), no effects on GST
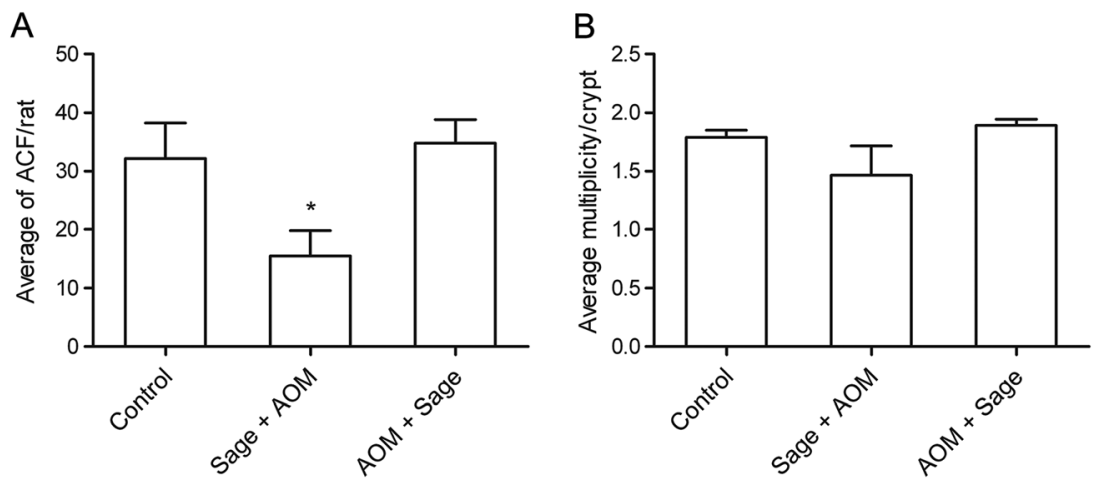

Figure 2. Effect of sage drinking in on AOM induction of ACF and multiplicity. (A) - Average number of ACF found in the whole colon after methylene blue staining. (B) - Average number of aberrant crypt per foci (multiplicity) per crypt in the colon. The results are expressed as mean \pm SEM for $n=6$. ${ }^{*} p<0.05$ when compared with water control. 

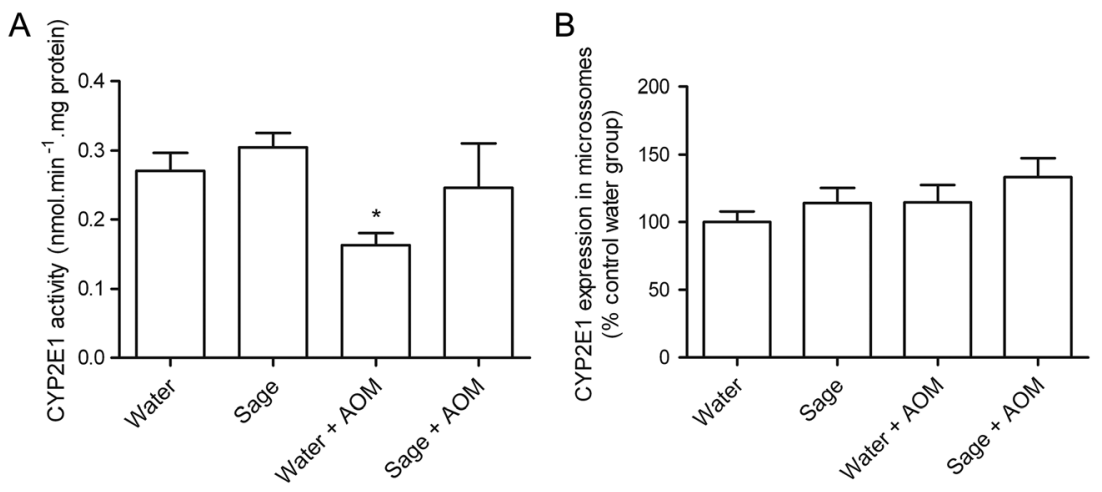

Figure 3. Effect of sage drinking (14 days) and/or AOM injection on cytochrome P450 2E1 (CYP2E1) activity (A) and levels (B) measured in the microsomal fraction isolated from rat liver. CYP2E1 activity is expressed as nmol. $\mathrm{min}^{-1}$. $\mathrm{mg}$ protein and protein levels expressed as percentage of water control group. The results are expressed as mean \pm SEM for $n=4$. ${ }^{*} p<0.05$ when compared with water control.

activity in any of the treatment groups were found (data not shown). Altogether, these results indicate that the preventive effect of sage tea on ACF formation was not due to decrease in AOM bioactivation or increase of AOM elimination.

The most important initiating factor in carcinogenesis is the occurrence of DNA damage and mutations. It is known that dietary mutagens and oxidative stress may lead to DNA damage. Dietary mutagens may be present in foods through fungal contamination or be the result of preservation and cooking. Examples of food mutagens are the heterocyclic amines 2-amino-1-methyl6-phenylimidazol[4,5-b]pyridine (PhIP) and 2-amino-3methylimidazol[4,5-f]quinoline (IQ), which are produced from cooking in protein-rich foods such as meat and fish

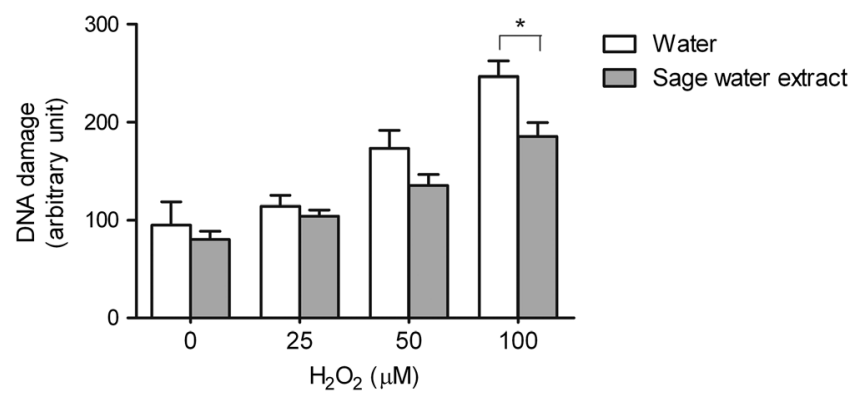

Figure 4. Effect of 2 weeks $\mathrm{SO}$ treatment in vivo on $\mathrm{H}_{2} \mathrm{O}_{2}$-induced DNA damage in isolated rat colonocytes. DNA damage analyzed by the comet assay. Mean $\pm \operatorname{SEM}(n=3)$. Statistical significances were determined using a two-way analysis of variance followed by Bonferroni's multiple comparison test. ${ }^{*} p<0.05$. that induce reactive oxygen species which in turn cause DNA damage (Derry et al., 2013). In our study, after bioactivation of AOM in the liver, methylazoxymethanol is transported to other organs where it will be further converted and finally, especially in the colon, induces DNA damage, suggesting that protection against DNA damage at the colonocyte level may be a relevant mechanism of chemoprevention.

Therefore, the effect of in vivo SO treatment on protection against in vitro $\mathrm{H}_{2} \mathrm{O}_{2}$-induced DNA damage in isolated colonocytes was investigated by the comet assay. Treatment with SO significantly decreased in vitro $\mathrm{H}_{2} \mathrm{O}_{2}$-induced DNA damage to colonocytes when compared with control (Fig. 4), which is in agreement with our previous in vitro results (Lima et al., 2007b; Ramos et al., 2010a). In vivo AOM-induced DNA damage to colonocytes was also evaluated. AOM was found to induce DNA damage detected by the comet assay, while SO treatment before AOM injection decreased DNA damage (Fig. 5A). In a study by Dolara et al., a protective effect of DNA damage in colonocytes was also found using wine polyphenols (Dolara et al., 2005) and a study from our lab demonstrated that $\mathrm{SO}$ extract exerts a protective effect against BCNU-induced DNA damage in a colon cell line (Ramos et al., 2012). In the present study, the same protective effect of SO against AOM-induced DNA damage was found in lymphocytes isolated from the same animals (Fig. 5B). This effect, as far as we know, has not been demonstrated in the literature and can be of great importance to further suggest lymphocytes as surrogate markers in these kinds of studies. The protective effects of SO may be due, at least in part, to an increase in
A

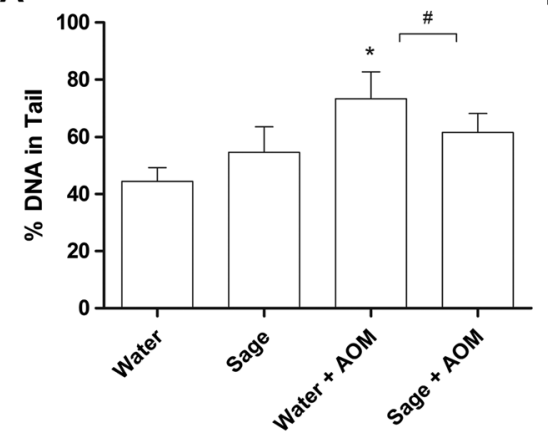

B

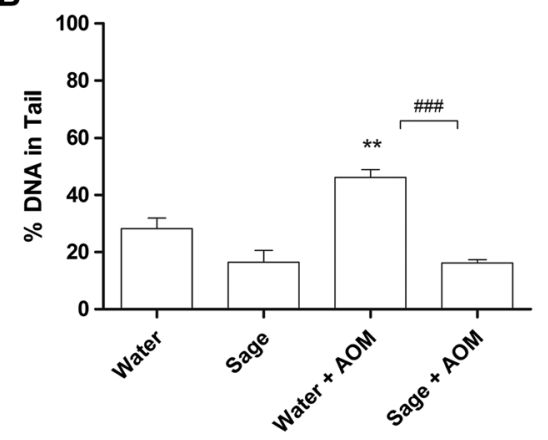

Figure 5. Effect of 2 weeks SO treatment and/or AOM injection on DNA damage on colonocytes (A) and lymphocytes (B) measured by the comet assay. DNA damage expressed as percentage of DNA in tail. The results are expressed as mean \pm SEM for $n=4$. ${ }^{*} p<0.05$ when compared with water control, $\# p<0.05$ when compared with water + AOM group, ${ }^{*} p<0.01$ when compared with water control, $\# \# \#<0.001$ when compared with water + AOM group. 


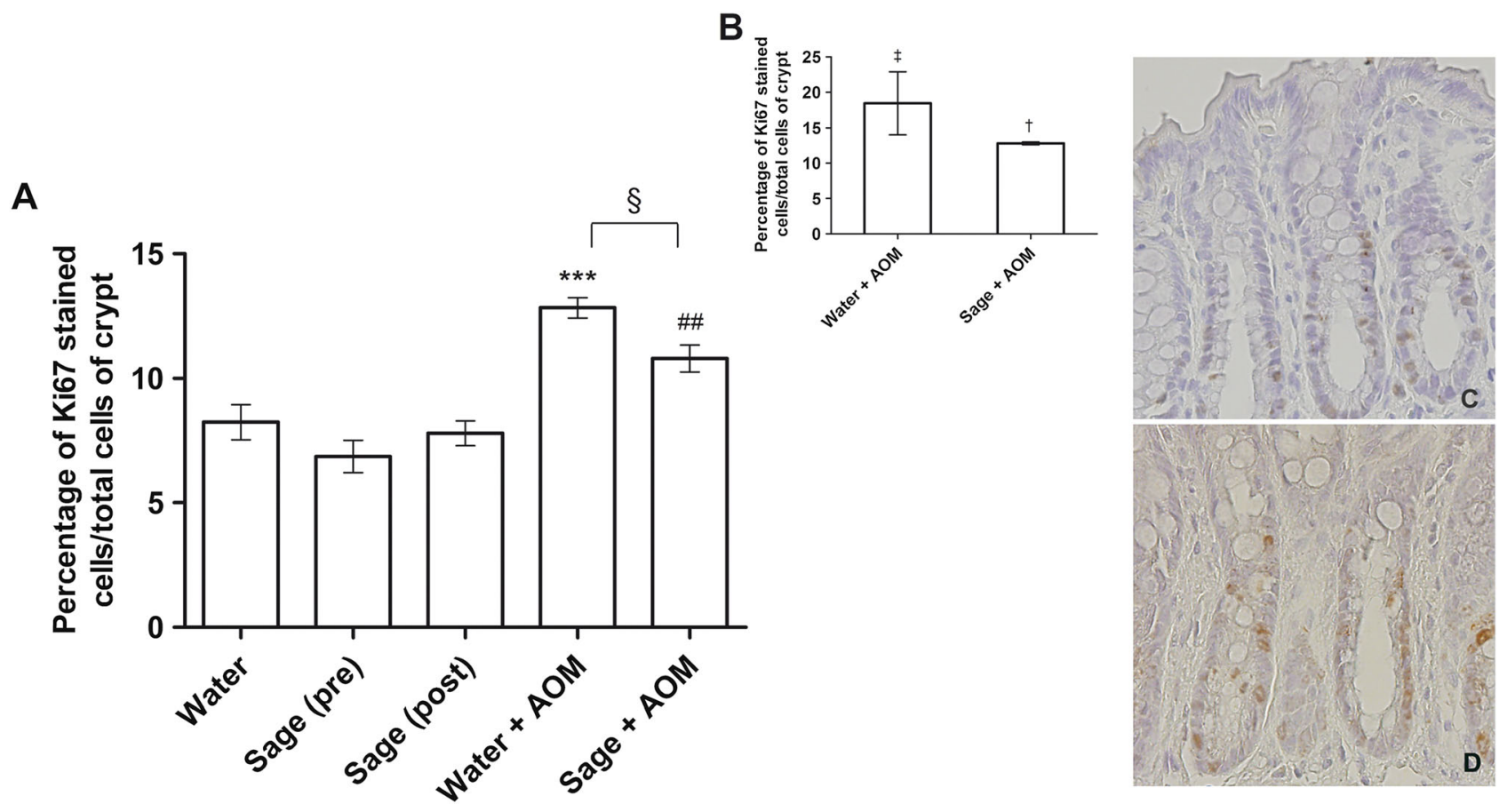

Figure 6. Proliferating cells in normal colon crypts of rats from water, sage (pre), sage (post), water $+\mathrm{AOM}$ and sage $+\mathrm{AOM}$ groups (A) and ACF from water + AOM and Sage + AOM groups (B) assayed for Ki67 expressing cells. Representative image of water group (C) and water + AOM group (D). Results are expressed as percentage of Ki67 stained cells per total number of cells in a crypt \pm SEM for $n=4$. $* * *=p<0.001$ when compared with water group, $\# \#=p<0.01$ when compared with sage (pre) group, $\S=p<0.05, \ddagger=p<0.05$ when compared with water $+\mathrm{AOM}$ group of normal tissue, $\dagger=p<0.05$ when compared with sage + AOM group of normal tissue. This figure is available in colour online at wileyonlinelibrary.com/journal/ptr.

protection against DNA damage, which seems to be a global effect and not just localized in the colon, and may be the key to chemoprevention of colon cancer. Protection against DNA damage is not only beneficial for cancer prevention but also for other diseases and the overall health of the individual.

It is also known that there is a link between chronic inflammation, proliferation and CRC (Hull, 2008; Itzkowitz, 2006; Terzic et al., 2010). The impact of SO on proliferation was evaluated in colon tissue, by Ki67 immunohistochemical staining of the colon mucosa. AOM increased the overall number of proliferating cells of the normal mucosa, but in animals treated with SO, this increase was significantly less pronounced (Fig. 6A). The number of proliferative cells was naturally also higher in ACF when compared with the respective normal tissue (Fig. 6B). Sage treatment was able to reduce the number of proliferating cells in the normal tissue, possibly as an effect of sage on different signalling pathways that regulate proliferation. A study from our lab showed that SO inhibits cell proliferation and inhibits the MAPK/ERK pathway in the KRAS mutated HCT15 cell line (Xavier et al., 2009).

The WNT signalling pathway is important in the regulation of cell proliferation in the colon crypt (Pinto and Clevers, 2005), and AOM may cause mutations in $\beta$-catenin, an intervenient in this pathway (Takahashi and Wakabayashi, 2004). In the present study, no $\beta$-catenin translocation to the nucleus was found in normal tissue or in ACF, and APC expression was the same in all groups (data not shown). AOM may not have caused alterations in $\beta$-catenin possibly because of the short duration of the study relative to the time these mutagenic lesions need to be expressed. So, SO chemoprevention appears to be, in addition to DNA protection from damage, also due to regulation of proliferation but does not appear to affect the regulation of the WNT signalling pathway (Takahashi et al., 2000; Takahashi and Wakabayashi, 2004). The MAPK/ERK pathway is usually also altered in this AOM-induced model. As it was referred before, SO has shown to inhibit this pathway in HCT15 cell line. As the WNT pathway was not altered, we could assume that sage tea is acting on the MAPK/ERK pathway. Studies in the activation of this pathway would answer this question.

\section{Azoxymethane}

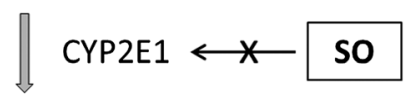

\section{Methylazoxymethanol}

$$
\text { SO }
$$

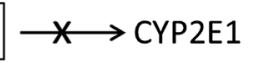

Methyldiazonium

ion
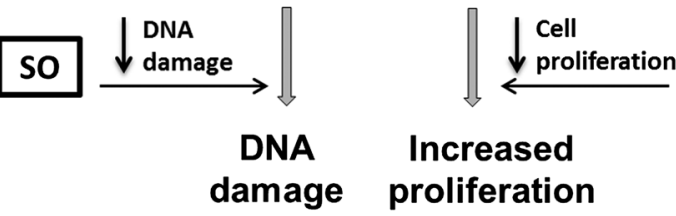

7. Overview of the relevant results obtained in this study and suggested mode of action of Salvia officinalis colon cancer chemoprevention. 
In conclusion, treatment with sage water extract (herbal tea) showed a chemopreventive effect against AOMinduced preneoplastic lesions of colon cancer (Fig. 7). An effect on colonocytes was demonstrated as SO treatment in vivo confers DNA protection against AOMinduced and $\mathrm{H}_{2} \mathrm{O}_{2}$-induced DNA damage. The protective effect of SO against DNA damage induced by AOM was also observed in lymphocytes. In addition, sage treatment significantly lowered the increased expression of Ki67, a marker of the overall proliferation rate in the colon. This study showed that the consumption of SO tea may contribute to prevention of colon cancer, and mechanisms of protection against DNA damage and modulation of cell proliferation are involved. Plant foods and beverages, such as SO tea, have shown great potential, and they should be considered as possible chemopreventive agents in dietary strategies against colon cancer. This herbal extract could ameliorate the overall health of the individual, not just against cancer initiation but also against other diseases associated with DNA damage.

\section{Acknowledgements}

We would like to thank Dr. Rodrigo Ozório (Auxiliar investigator at the Centro Interdisciplinar de Investigação Marinha e Ambiental, Porto) for his help in the preparation of the AIN76-based rat chow and Professor Fernando Schmitt (IPATIMUP, Porto, Portugal) for his help in the interpretation of the $\beta$-catenin results. Ramos AA and Pedro DFN are supported by the Foundation for Science and Technology, Portugal, grant SFRH/BD/35672/2007 and SFRH/BD/64817/2009, respectively.

\section{Conflict of Interest}

The authors declare no conflict of interest.

\section{REFERENCES}

Allis JW, Robinson BL. 1994. A kinetic assay for p-nitrophenol hydroxylase in rat liver microsomes. Anal Biochem 219: 49-52.

Andersson D, Cheng Y, Duan RD. 2008. Ursolic acid inhibits the formation of aberrant crypt foci and affects colonic sphingomyelin hydrolyzing enzymes in azoxymethane-treated rats. J Cancer Res Clin Oncol 134: 101-107.

Barbier O, Lapointe H, El Alfy M, et al. 2000. Cellular localization of uridine diphosphoglucuronosyltransferase $2 \mathrm{~B}$ enzymes in the human prostate by in situ hybridization and immunohistochemistry. J Clin Endocrinol Metab 85: 4819-4826.

Caderni G, De Filippo C, Luceri C, et al. 2000. Effects of black tea, green tea and wine extracts on intestinal carcinogenesis induced by azoxymethane in F344 rats. Carcinogenesis 21: 1965-1969.

Collins AR. 2004. The comet assay for DNA damage and repair: principles, applications, and limitations. Mol Biotechnol 26: 249-261.

Derry MM, Raina K, Agarwal C, et al. 2013. Identifying molecular targets of lifestyle modifications in colon cancer prevention. Front Oncol 3: 1-20.

Dolara P, Luceri C, De Filippo C, et al. 2005. Red wine polyphenols influence carcinogenesis, intestinal microflora, oxidative damage and gene expression profiles of colonic mucosa in F344 rats. Mutat Res 591: 237-246.

Gosslau A, En Jao DL, Huang M-T, et al. 2011. Effects of the black tea polyphenol theaflavin-2 on apoptotic and inflammatory pathways in vitro and in vivo. Mol Nutr Food Res 55: 198-208.

Hull M. 2008. Molecular pathways leading to cancer as a basis for preventive strategies. Curr Colorectal Cancer Rep 4: 43-47.

Itzkowitz SH. 2006. Molecular biology of dysplasia and cancer in inflammatory bowel disease. Gastroenterol Clin North Am 35: 553-571.

Johnson RL, Fleet JC. 2013. Animal models of colorectal cancer. Cancer Metastasis Rev 32: 39-61.

Lima CF, Andrade PB, Seabra RM, et al. 2005. The drinking of a Salvia officinalis infusion improves liver antioxidant status in mice and rats. J Ethnopharmacol 97: 383-389.

Lima CF, Fernandes-Ferreira M, Pereira-Wilson C. 2007a. Drinking of Salvia officinalis tea increases $\mathrm{CCl}(4)$-induced hepatotoxicity in mice. Food Chem Toxicol 45: 456-464.

Lima CF, Valentao PC, Andrade PB, et al. 2007b. Water and methanolic extracts of Salvia officinalis protect HepG2 cells from tBHP induced oxidative damage. Chem Biol Interact 167: 107115.

Lord CJ, Ashworth A. 2012. The DNA damage response and cancer therapy. Nature 481: 287-294.

Miura K, Kikuzaki H, Nakatani N. 2002. Antioxidant activity of chemical components from sage (Salvia officinalis L.) and thyme (Thymus vulgaris L.) measured by the oil stability index method. J Agric Food Chem 50: 1845-1851.

Mori H, Yamada Y, Kuno T, et al. 2004. Aberrant crypt foci and beta-catenin accumulated crypts; significance and roles for colorectal carcinogenesis. Mutat Res 566: 191-208.
Padidar S, Farquharson A, Williams L, et al. 2012. High-Fat diet alters gene expression in the liver and colon: links to increased development of aberrant crypt foci. Dig Dis Sci 1-9.

Pan MH, Lai CS, Wu JC, et al. 2011. Molecular mechanisms for chemoprevention of colorectal cancer by natural dietary compounds. Mol Nutr Food Res 55: 32-45.

Peltomaki P. 2001. Deficient DNA mismatch repair: a common etiologic factor for colon cancer. Hum Mol Genet 10: 735-740.

Pinto D, Clevers H. 2005. Wnt, stem cells and cancer in the intestine. Biol Cell 97: 185-196.

Ramos AA, Azqueta A, Pereira-Wilson C, et al. 2010a. Polyphenolic compounds from Salvia species protect cellular DNA from oxidation and stimulate DNA repair in cultured human cells. $J$ Agric Food Chem 58: 7465-7471.

Ramos AA, Pereira-Wilson C, Collins AR. 2010b. Protective effects of ursolic acid and luteolin against oxidative DNA damage include enhancement of DNA repair in Caco-2 cells. Mutat Res 692: 6-11.

Ramos AA, Pedro D, Collins AR, et al. 2012. Protection by Salvia extracts against oxidative and alkylation damage to DNA in human HCT15 and C0115 cells. J Toxicol Environ Health $A$ 75: 765-775.

Sa CM, Ramos AA, Azevedo MF, et al. 2009. Sage tea drinking improves lipid profile and antioxidant defences in humans. Int $J$ Mol Sci 10: 3937-3950.

Sohn OS, Fiala ES, Requeijo SP, et al. 2001. Differential effects of CYP2E1 status on the metabolic activation of the colon carcinogens azoxymethane and methylazoxymethanol. Cancer Res 61: 8435-8440.

Takahashi M, Wakabayashi K. 2004. Gene mutations and altered gene expression in azoxymethane-induced colon carcinogenesis in rodents. Cancer Sci 95: 475-480.

Takahashi M, Mutoh M, Kawamori T, et al. 2000. Altered expression of beta-catenin, inducible nitric oxide synthase and cyclooxygenase- 2 in azoxymethane-induced rat colon carcinogenesis. Carcinogenesis 21: 1319-1327.

Tang F-Y, Pai M-H, Chiang E-PI. 2012. Consumption of high-fat diet induces tumor progression and epithelial-mesenchymal transition of colorectal cancer in a mouse xenograft model. $J$ Nutr Biochem 23: 1302-1313.

Terzic J, Grivennikov S, Karin E, et al. 2010. Inflammation and colon cancer. Gastroenterology 138: 2101-2114 e2105.

Toden S, Lockett TJ, Topping DL, et al. 2014. Butyrylated starch affects colorectal cancer markers beneficially and dosedependently in genotoxin-treated rats. Cancer Biol Ther 15: 1515-1523.

Topcu G. 2006. Bioactive triterpenoids from Salvia species. J Nat Prod 69: 482-487.

Weber LW, Boll M, Stampfl A. 2003. Hepatotoxicity and mechanism of action of haloalkanes: carbon tetrachloride as a toxicological model. Crit Rev Toxico/ 33: 105-136.

Xavier CP, Lima CF, Fernandes-Ferreira M, et al. 2009. Salvia fruticosa, Salvia officinalis and rosmarinic acid induce apoptosis 
and inhibit proliferation of human colorectal cell lines: the role in MAPK/ERK pathway. Nutr Cancer 61: 564-571.

Xavier CP, Lima CF, Pedro DNF et al. 2013. Ursolic acid induces cell death and modulates autophagy through JNK pathway in apoptosis-resistant colorectal cancer cells. J Nutr Biochem 24: 706-712.
Zhukov A, Ingelman-Sundberg M. 1999. Relationship between cytochrome P450 catalytic cycling and stability: fast degradation of ethanol-inducible cytochrome P450 2E1 (CYP2E1) in hepatoma cells is abolished by inactivation of its electron donor NADPH-cytochrome P450 reductase. Biochem J 340(Pt 2): 453-458. 